\title{
Epithelial-Mesenchymal Transition in Chronic Rhinosinusitis: Differences Revealed Between Epithelial Cells from Nasal Polyps and Inferior Turbinates
}

\author{
Michael Könnecke ${ }^{1} \cdot$ Maike Burmeister $^{1} \cdot$ Ralph Pries $^{1} \cdot$ Robert Böscke $^{1}$ • \\ Karl-Ludwig Bruchhage ${ }^{1} \cdot$ Hendrik Ungefroren $^{2} \cdot$ Ludger Klimek $^{3}$ • \\ Barbara Wollenberg ${ }^{1}$
}

Received: 10 August 2015/Accepted: 29 April 2016/Published online: 8 July 2016

(C) L. Hirszfeld Institute of Immunology and Experimental Therapy, Wroclaw, Poland 2016

\begin{abstract}
The pathogenesis of chronic rhinosinusitis (CRS) remains unclear to date. The tissue remodeling in nasal polyps may be the result of inflammatory mediators and may involve epithelial-mesenchymal transition (EMT) and EMT-associated features such as cell motility in nasal epithelial cells (NECs). We determined whether NEC in nasal polyps of CRS already display features of EMT in vivo or respond with EMT to growth factor stimulation in vitro. Nasal polyp tissues expressed both epithelial and mesenchymal markers. Primary NEC from inferior turbinates and nasal polyps responded to the EMT-inducing agents transforming growth factor (TGF)- $\beta 1$ and epidermal growth factor (EGF) with different expression patterns of EMT markers (E-cadherin, N-cadherin, Snail, Slug, Twist), however, only NEC from nasal polyps were susceptible to TGF- $\beta 1$ and EGF-dependent cell migration. Our data suggest that a partial EMT is associated with the pathogenesis of nasal polyps in CRS patients. Furthermore, we show for the first time that epithelial cells from both nasal polyps and inferior turbinates were able to undergo an EMT-like process following exposure to TGF- $\beta 1$ or EGF in vitro but that only NEC from nasal polyps responded
\end{abstract}

Electronic supplementary material The online version of this article (doi:10.1007/s00005-016-0409-7) contains supplementary material, which is available to authorized users.

Michael Könnecke

Michael.Koennecke@uksh.de

1 Department of Otorhinolaryngology, University Hospital Schleswig-Holstein, Campus Lübeck, Ratzeburger Allee 160, 23538 Lübeck, Germany

2 First Department of Medicine, University Hospital Schleswig-Holstein, Campus Lübeck, Lübeck, Germany

3 Center for Rhinology and Allergology, Wiesbaden, Germany with enhanced cell motility. Our data suggest that NEC from CRS patients have undergo partial EMT and that this process may be involved in the pathogenesis of CRS.

Keywords Chronic rhinosinusitis with nasal polyps . CRSwNP · Nasal polyps · Nasal epithelial cells . Epithelial-mesenchymal transition · EMT

\section{Introduction}

Chronic rhinosinusitis (CRS) is a significant health problem (Hastan et al. 2011) and recent data have illustrated that CRS affects about 5-15\% of the population in Europe and the USA (Fokkens et al. 2012). Chronic rhinosinusitis with nasal polyps (CRSwNP) is considered a subgroup of CRS, a chronic inflammatory condition of the nasal and paranasal sinuses and is characterized by grape-like structures in the upper nasal cavity. Typical histological features of nasal polyps are dense inflammatory infiltrates, loose fibrous connective tissue with substantial tissue edema and a thickened basement membrane covered mostly by respiratory pseudostratified epithelium (Fokkens et al. 2012). The current model of pathogenesis in nasal polyps comprises four steps, starting with an intrinsic host deficit, resulting in impaired release of innate host defense molecules, followed by colonization with bacteria with the loss of the natural barrier function. A local elevation of pathogen-associated molecular patterns and antigen-driven activation of the adaptive immune system (superantigen effect) generates an inflammatory local microenvironment which per se drives the development of inflammation and autoimmunity (Fokkens et al. 2012; Tan et al. 2010). However, the pathogenesis of CRSwNP and its proliferative benign nature remains unclear. 
A typical response to this chronic inflammation is tissue remodeling (Fokkens et al. 2012). This is a dynamic process involving a structural reorganization of tissues (Van Bruaene and Bachert 2011). Different chronic inflammatory lower airway disorders, like cystic fibrosis and asthma, have been linked to characteristic patterns of airway remodeling (Al-Muhsen et al. 2011). Remodeling also takes place in the upper airway during chronic inflammation like allergic rhinitis or CRS, including inflammatory cell infiltrates, basement membrane thickening, sub-epithelial edema and fibrosis (Kim et al. 2010; Rehl et al. 2007). To date, the mechanism of this tissue remodeling is not fully understood but may involve epithelial-mesenchymal transition (EMT). EMT is a cellular process in which epithelial cells loose their epithelial character and gain mesenchymal properties and eventually contribute to the local fibroblast pool (Hackett et al. 2009; Kalluri and Neilson 2003). It plays important roles in embryonic development and tissue homeostasis, but it is also implicated in wound healing, fibrosis, tumor invasion and metastasis (Thiery et al. 2009). During EMT, the epithelial marker protein E-cadherin is down-regulated while the mesenchymal markers N-cadherin and Snail are up-regulated, ultimately resulting in weak cell-to-cell contacts and increased motility (Lee et al. 2006). The loss of E-cadherin expression is a fundamental event in EMT and factors capable of suppressing E-cadherin function as full EMT inducers in many cell contexts (Thiery et al. 2009).

In this study, we hypothesized that the chronic inflammatory condition of CRS leads to tissue remodeling and EMT during to polyp formation. According to this assumption, expression of EMT markers was verified in nasal polyps and inferior turbinates of CRS patients. Additionally, nasal epithelial cells (NEC) were analyzed in vitro by gene expression profiling and migration assays for their capacity to undergo EMT upon exposure to adequate stimuli.

\section{Materials and Methods}

\section{Ethics Statement}

All patients were treated surgically at the Department of Otorhinolaryngology, University Hospital Schleswig-Holstein, Campus Lübeck, and have given their written informed consent. The study was approved by the local ethics committee of the University of Lübeck and conducted in accordance with the ethical principles for medical research formulated in the WMA Declaration of Helsinki.

\section{Patient Specimens}

Nasal polyp tissue, associated inferior turbinate tissue, as internal control, and healthy inferior turbinate tissue were harvested from 40 patients with mean age of $46.72 \pm 16.06$, distributed in 29 males (mean age $50.41 \pm 16.38$ ) and 11 females (mean age $40.45 \pm 13.28$ ), who underwent functional endoscopic sinus surgery or septoplasty with reduction of the inferior turbinates (Table 1). Fresh tissue samples were flash frozen in liquid nitrogen immediately after resection, stored at $-80{ }^{\circ} \mathrm{C}$ before RNA and protein extraction and additionally used for isolation of NEC. For microarray analysis, nasal polyp tissue and inferior turbinate tissue of eight patients ( 7 males and 1 female; mean age $53.87 \pm 13.34$ ) was representatively analyzed.

All patients had a history of sinusitis of more than 3 months and did not respond to conservative therapy. Patients were skin tested for pollens, molds, dust mites, and pets using standardized extracts (Allergopharma Joachim Ganzer KG, Reinbek, Germany) within a time frame of 4 weeks before surgery. Eosinophilic CRSwNP was determined by histopathologic examination and patients with mucoviscidosis or neutrophilic nasal polyps were not included in this study. All patients had been free of steroid medication for at least 4 weeks before surgery and had no history of atopy, bronchial asthma or salicylate intolerance/ aspirin-exacerbated respiratory disease.

\section{Microarrays}

Frozen tissue samples were shipped on dry ice to Miltenyi Biotec (Bergisch Gladbach, Germany) for Agilent Whole Human Genome Microarray $(4 \times 44 \mathrm{~K})$ analysis. RNAs were isolated using standard RNA extraction protocols (Trizol) and were quality-checked via the Agilent 2100 Bioanalyzer platform (Agilent Technologies). The RIN value was calculated and RNA with a RIN number $>6$ was used (Fleige and Pfaffl 2006). The Rosetta Resolver ${ }^{\circledR}$ gene expression data analysis system (Rosetta Biosoftware) was used to compare two single intensity profiles in a ratio experiment. These experiments adhere to the Minimal Information About A Microarray Experiment guidelines.

\section{Quantitative Real-Time PCR}

Quantitative real-time PCR (qPCR) was performed to confirm microarray results and to analyze EMT marker after stimulation, using TaqMan ${ }^{\circledR}$ Gene Expression Assays (Applied Biosystems, Foster City, CA, USA; Table 2). The 
Table 1 Patient demographics

\begin{tabular}{|c|c|c|c|c|c|}
\hline Patient & Gender & Age (years) & Disease & Medication & Cell source \\
\hline 1 & Male & 55 & CRSwNP & None & NP, IT \\
\hline 2 & Female & 42 & CRSwNP & None & NP, IT \\
\hline 3 & Male & 44 & CRSwNP & None & NP, IT \\
\hline 4 & Male & 84 & CRSwNP & None & NP, IT \\
\hline 5 & Male & 31 & CRSwNP & None & NP, IT \\
\hline 6 & Male & 70 & CRSwNP & None & NP, IT \\
\hline 7 & Male & 61 & CRSwNP & None & NP, IT \\
\hline 8 & Male & 61 & CRSwNP & None & NP, IT \\
\hline 9 & Male & 50 & CRSwNP & None & NP, IT \\
\hline 10 & Male & 39 & CRSwNP & None & NP, IT \\
\hline 11 & Male & 37 & CRSwNP & None & NP, IT \\
\hline 12 & Female & 43 & CRSwNP & None & NP, IT \\
\hline 13 & Female & 54 & CRSwNP & None & NP, IT \\
\hline 14 & Male & 61 & CRSwNP & None & NP, IT \\
\hline 15 & Male & 33 & CRSwNP & None & NP, IT \\
\hline 16 & Male & 58 & CRSwNP & None & NP, IT \\
\hline 17 & Male & 74 & CRSwNP & None & NP, IT \\
\hline 18 & Male & 48 & CRSwNP & None & NP, IT \\
\hline 19 & Male & 45 & CRSwNP & None & NP, IT \\
\hline 20 & Male & 31 & CRSwNP & None & NP, IT \\
\hline 21 & Male & 54 & CRSwNP & None & NP, IT \\
\hline 22 & Male & 80 & CRSwNP & None & NP, IT \\
\hline 23 & Male & 57 & CRSwNP & None & NP, IT \\
\hline 24 & Male & 54 & CRSwNP & None & NP, IT \\
\hline 25 & Male & 33 & CRSwNP & None & NP, IT \\
\hline 26 & Female & 55 & CRSwNP & None & NP, IT \\
\hline 27 & Male & 77 & CRSwNP & None & NP, IT \\
\hline 28 & Male & 54 & CRSwNP & None & NP, IT \\
\hline 29 & Male & 44 & CRSwNP & None & NP, IT \\
\hline 30 & Female & 54 & CRSwNP & None & NP, IT \\
\hline 31 & Female & 38 & None & None & hIT \\
\hline 32 & Female & 30 & None & None & hIT \\
\hline 33 & Male & 39 & None & None & hIT \\
\hline 34 & Male & 36 & None & None & hIT \\
\hline 35 & Female & 20 & None & None & hIT \\
\hline 36 & Female & 56 & None & None & hIT \\
\hline 37 & Male & 31 & None & None & hIT \\
\hline 38 & Male & 21 & None & None & hIT \\
\hline 39 & Female & 24 & None & None & hIT \\
\hline 40 & Female & 29 & None & None & hIT \\
\hline
\end{tabular}

transcriptional activity of the genes studied was analyzed using a LightCycler 1.5 (Roche, Mannheim, Germany). Messenger RNA was isolated using the RNeasy Plus Mini Kit (Qiagen, Hilden, Germany) and was subjected to cDNA synthesis using the RevertAid ${ }^{\mathrm{TM}}$ First Strand cDNA Synthesis Kit (Fermentas, St. Leon-Rot, Germany).
Corresponding controls were carried out and experiments were performed according to the manufacturer's instructions. Five ng of cDNA was used for qPCR. Detailed program information was published before (Könnecke et al. 2014). To ensure that the reference gene was stably expressed in nasal polyps and inferior turbinates, we tested 
Table 2 TaqMan $^{\circledR}$ gene expression assays used for $\mathrm{qPCR}$

\begin{tabular}{|c|c|c|c|}
\hline Gene symbol & Assay ID & GeneBank & $\begin{array}{l}\text { Length of } \\
\text { amplicon (bp) }\end{array}$ \\
\hline$\beta$-Actin & Hs99999903_m1 & NM_001101.3 & 171 \\
\hline E-cadherin & Hs01023894_m1 & NM_004360.3 & 61 \\
\hline $\mathrm{N}$-cadherin & Hs00983056_m1 & NM_001792.3 & 66 \\
\hline Snail & Hs00195591_m1 & NM_005985.3 & 66 \\
\hline Slug & Hs00950344_m1 & NM_003068.3 & 56 \\
\hline Twist & Hs00361186_m1 & NM_000474.3 & 115 \\
\hline Fibronectin 1 & Hs01549976_m1 & $\begin{array}{l}\text { NM_212474.1, NM_212475.1, NM_212476.1, NM_212478.1, } \\
\quad \text { NM_212482.1, NM_002026.2, NM_054034.2 }\end{array}$ & 81 \\
\hline Vimentin & Hs00185584_m1 & NM_003380.3 & 73 \\
\hline TGF- $\beta 1$ & Hs00998133_m1 & NM_000660.4 & 57 \\
\hline TGF- $\beta 2$ & Hs00234244_m1 & NM_001135599.2, NM_003238.3 & 92 \\
\hline TGF- $\beta 3$ & Hs01086000_m1 & NM_003239.2 & 63 \\
\hline Smad2 & Hs00998182_m1 & NM_001003652.3, NM_001135937.2, NM_005901.5 & 119 \\
\hline Smad3 & Hs00706299_s1 & NM_001145102.1, NM_001145103.1, NM_001145104.1, NM_005902.3 & 64 \\
\hline Smad7 & Hs00998193_m1 & NM_001190821.1, NM_001190822.1, NM_001190823.1, NM_005904.3 & 105 \\
\hline
\end{tabular}

several housekeeping genes such as $\beta$-actin, GAPDH or HPRT1 according to the Minimum Information for Publication of Quantitative Real-Time PCR Experiments Guidelines. The $\beta$-actin gene was invariantly expressed under experimental conditions, thus all selected gene mRNA levels in patients were measured and normalized to $\beta$-actin. The $2^{-\Delta \Delta C_{\mathrm{t}}}$ method (Livak and Schmittgen 2001) was used to analyze the qPCR data.

\section{Western Blotting}

Tissues were homogenized and proteins were isolated using RIPA-buffer (Cell Signaling, Danvers, MA, USA) containing $60 \mu \mathrm{l}$ Aprotinin, $20 \mu \mathrm{l}$ PMSF, $20 \mu \mathrm{l}$ Pepstatin A, $40 \mu \mathrm{l}$ Natriumfluorid and $20 \mu \mathrm{l}$ Phosphatase Inhibitor Cocktail for each tissue. Equal amounts of proteins were separated by SDS-polyacrylamide gel electrophoresis using a $4-20 \%$ Mini-PROTEAN ${ }^{\circledR}$ TGX $^{\mathrm{TM}}$ Precast Gel (Bio-Rad, Hercules, CA, USA) containing internal standards (Protein Marker V, Peqlab, Erlangen, Germany) and transferred on an Immobilon ${ }^{\mathrm{TM}}-\mathrm{P}$ transfer membrane (EMD Millipore Corporation, Billerica, MA, USA). Blots were blocked in Tris-buffered saline (TBS) containing $5 \%$ bovine serum albumin (BSA) for $60 \mathrm{~min}$ at room temperature and incubated overnight at $4{ }^{\circ} \mathrm{C}$ with specific antibodies against E-cadherin, $\mathrm{N}$-cadherin and vimentin (EMT Antibody Sampler Kit, Cell Signaling Danvers, MA, USA) diluted 1:1000 in TBS containing $3 \%$ BSA. After incubation with the corresponding secondary antibody, protein bands were detected on the Fusion FX7 (Vilber Lourmat, Torcy,
France) using the electrochemiluminescence method (Amersham Biosciences, Buckinghamshire, UK). Glycerinaldehyd-3-phosphat-Dehydrogenase (GAPDH; Cell Signaling, Danvers, MA, USA) was used as loading control.

\section{Transforming Growth Factor $\beta 1$ ELISA}

Quantitative ELISA for transforming growth factor (TGF)$\beta 1$ was performed in tissue lysates of nasal polyps $(n=6)$ and inferior turbinates $(n=3)$ of CRSwNP patients using a Quantikine human TGF- $\beta 1$ immunoassay (R\&D Systems, Minneapolis, MN, USA) according to the manufacturer's instructions. Results were adjusted to different protein content of lysates.

\section{Isolation of Primary Human NEC and Stimulation of EMT}

Fresh tissue samples of nasal polyps and inferior turbinates from multiple patients were transported in sterile containers containing sterile chilled Ringer's solution, transferred into $10-\mathrm{ml}$ protease dissociation medium $(0.1 \%$ protease XIV in RPMI 1640) and placed on a platform rocker at $4{ }^{\circ} \mathrm{C}$ for $24 \mathrm{~h}$. Epithelial cells were removed by gently scraping the epithelial surface with a convex surgical blade. Dissociated cells were transferred into a $50-\mathrm{ml}$ conical tube, centrifuged at $200 \mathrm{~g}$ for $5 \mathrm{~min}$ and resuspended in epithelial culture medium (BEGM, Lonza, Group Ltd, Basel, Schweiz). Primary cells were plated on type IV collagen-coated 6-well tissue culture plates 
Table 3 Cell numbers used for experiments

\begin{tabular}{lrl}
\hline Methods & Cell numbers & $\begin{array}{l}\text { Surface areas } \\
\left(\mathrm{cm}^{2} / \text { well }\right)\end{array}$ \\
\hline Immunofluorescence & $1 \times 10^{5}$ & 1.7 \\
MTT assay & $5 \times 10^{3}$ & 0.32 \\
qPCR & $7.5 \times 10^{4}$ & 3.7 \\
RTCA-migration & $2 \times 10^{4}$ & 0.32 \\
\hline
\end{tabular}

$\left(6 \mu \mathrm{g} / \mathrm{cm}^{2}\right)$, and cultured at $37{ }^{\circ} \mathrm{C}$ and $10 \% \mathrm{CO}_{2}$. Medium was changed every 2-3 days. For EMT induction, cells were plated in different densities (Table 3) and either untreated or treated with $10 \mathrm{ng} / \mathrm{ml}$ recombinant human TGF- $\beta 1$ (ReliaTech GmbH, Wolfenbüttel, Germany) or $50 \mathrm{ng} / \mathrm{ml}$ recombinant human epidermal growth factor (EGF; R\&D Systems, Minneapolis, MN, USA) for 6, 12, 24 and $48 \mathrm{~h}$. To eliminate the possibility of contamination of NEC with fibroblasts, NEC cultures were grown in serum-free medium to disable fibroblast growth and untreated cell cultures showed no mesenchymal phenotype. Additionally, NEC derived from multiple patients where used separately for each experiment and were not pooled. Stimulation experiments consist of a minimum of three independent experiments.

\section{Immunofluorescence}

After $48 \mathrm{~h}$, stimulated cells were fixed in $4 \%$ paraformaldehyde (PFA) containing $0.1 \%$ Triton X100 for $10 \mathrm{~min}$, incubated overnight with mouse monoclonal antibody E-cadherin (1:50; ab1416, Abcam PLC, Cambridge, MA, USA), washed three times in phosphate buffered saline (PBS) and were incubated with anti-mouse Cy2 (1:100, Jackson Immuno Research, West Grove, PA, USA) for $45 \mathrm{~min}$. Additionally, cells were stained with phalloidin (Dy-547-Phalloidin, Dyomics, Jena, Germany), to evaluate cell morphology, and DAPI (Roche, Mannheim, Germany) for nuclear staining. Additional controls were included. The cells were observed under an Axiovert $200 \mathrm{M}$ microscope (Carl Zeiss AG, Oberkochen, Germany).

\section{Real-Time Cell Analysis Assay}

Using the xCELLigence ${ }^{\mathrm{TM}}$ System (OLS, Bremen, Germany, formerly: Roche, Mannheim, Germany) real-time measurements of random cell migration on NECs were performed $(n=3)$. CIM-Plates 16 were coated with type IV collagen $\left(6 \mu \mathrm{g} / \mathrm{cm}^{2}\right)$. TGF- $\beta 1$ or EGF were separately added to both chambers at the same concentration. The real-time cell analysis assay was performed according to the manufacturer's instructions. Data were acquired every minute over a total period of $24 \mathrm{~h}$. The assay was performed in triplicates.

\section{Metabolic Activity of NECs}

The metabolic MTT assay (3-(4,5-dimethylthiazol-2-yl)2,5-diphenyltetrazolium bromide) was used to assess the effect of TGF- $\beta 1$ and EGF on cell viability of NECs (Sieuwerts et al. 1995). Viable respiring cells convert the water-soluble MTT to an insoluble purple formazan. The concentration of formazan was determined by optical density after previous solubilization. The optical density of the purple formazan correlates with the metabolic activity and is proportional to the number of viable cells (Kupcsik 2011; Mosmann 1983). To measure the metabolic activity, NECs were seeded into a 96-well tissue culture microtiter plate at $5 \times 10^{3}$ cells per well in $100 \mu$ culture medium. Cell viability was measured after 12,24 and $48 \mathrm{~h}$ by the reduction of MTT in a colorimetric assay. $10 \mu \mathrm{l}$ MTT was added to each well and incubated for $2 \mathrm{~h}$ in the dark at $37^{\circ} \mathrm{C}$. The conversion was stopped by adding $100 \mu \mathrm{l}$ of MTT stop solution and after incubation in the dark at room temperature on a shaking plate rocker for $24 \mathrm{~h}$ the optical density was measured at $570 \mathrm{~nm}$ versus a reference wavelength at $690 \mathrm{~nm}$ with a Benchmark Plus ${ }^{\mathrm{TM}}$ Microplate Spectrophotometer (Bio-Rad Laboratories $\mathrm{GmbH}$, München). The assay was performed in quadruplicate.

\section{Statistical Analysis}

For statistical analysis and graphs, Prism software (GraphPad, San Diego, USA) was used. Experiments were performed in triplicates. Means and standard deviations were compared using Wilcoxon matched-pairs signed rank test or two-way ANOVA. $P$ values $\leq 0.05$ were considered to be statistically significant.

\section{Results}

\section{Gene Expression Analysis (Microarray, qRT-PCR) and Protein Expression in Tissue of Native Polyps and Inferior Turbinates}

The microarray analysis of tissue of eight pairs of nasal polyps and the corresponding inferior turbinate showed a trend towards a decrease of $\mathrm{N}$-cadherin expression (0.62-fold, $n=8$ ) in nasal polyps (Fig. 1a). Expression of E-cadherin (1.2-fold, $n=8)$, fibronectin 1 (1.32-fold, $n=8)$, vimentin (0.76-fold, $n=8$ ), Snail (0.86-fold, $n=8$ ), Slug (1.4-fold, $n=8$ ) and Twist (1.16-fold, $n=8$ ) was not significantly different in inferior turbinates and nasal polyps. 
Fig. 1 a Scatter plot of EMT marker in nasal polyps (median is indicated as horizontal bar) using microarray analysis. A trend to decrease of $\mathrm{N}$-cadherin (0.62-fold, $n=8$ ) was observed in nasal polyps (a). The gene expression of E-cadherin (1.2fold, $n=8$ ), fibronectin 1 (1.32-fold, $n=8)$, vimentin (0.76-fold, $n=8)$, Snail (0.86fold, $n=8$ ), Slug (1.4-fold, $n=8$ ) and Twist (1.16-fold, $n=8$ ) was not different between inferior turbinates and nasal polyps. b Scatter plot of EMT marker in nasal polyps (median is indicated as horizontal bar) using qPCR. Although not statistically significant, lower median expression of $\mathrm{N}$-cadherin, Snail and vimentin (0.62- to 0.72 fold, $n=8$ ) was observed in nasal polyps. The median expression of E-cadherin, Slug, fibronectin 1 and Twist showed no significant difference between nasal polyps and inferior turbinates (0.98- to 1.12-fold, $n=8$ ). Statistical significance was assessed by Wilcoxon matched-pairs signed rank test. c Scatter plot of EMT markers in nasal polyps compared to healthy inferior turbinates $(n=8)$. Nasal polyps exhibited a higher expression of E-cadherin (3.52-fold), $\mathrm{N}$-cadherin (3.72-fold), fibronectin 1 (8.91-fold), vimentin (7.53-fold), Snail (5.06-fold), Slug (9.00-fold) and Twist (57.86-fold) when compared to healthy inferior turbinates. Slug and Twist expression was significantly higher in nasal polyps compared to healthy inferior turbinates $(p<0.05$ and $p \leq 0.001$, $n=8)$ than compared to the inferior turbinate of the same patients (b). Statistical significance was assessed by Wilcoxon matched-pairs signed rank test
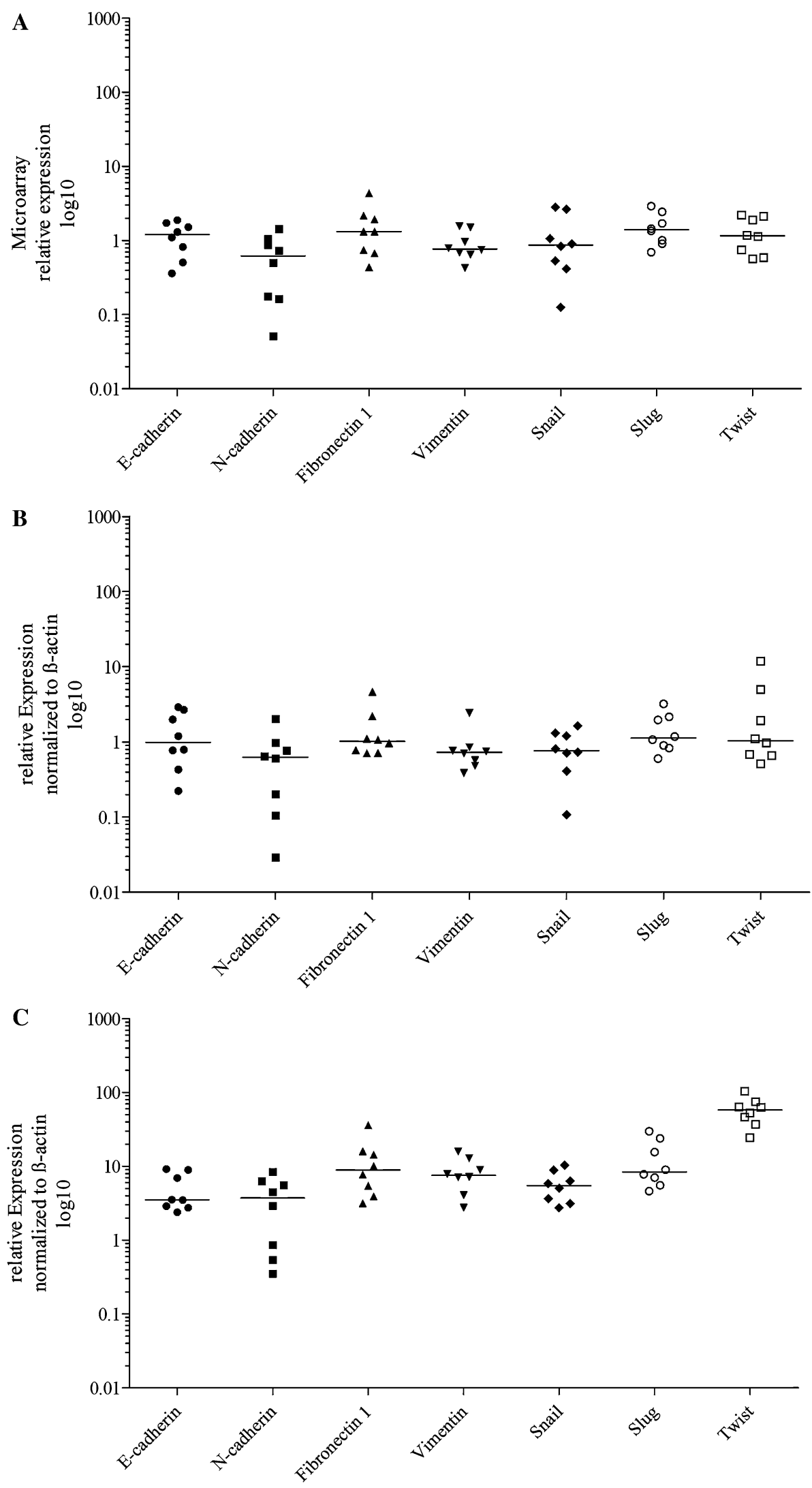
To confirm the data obtained by microarray analysis, we studied the mRNA expression of EMT markers using qPCR. Expression of N-cadherin (0.62-fold, $n=8)$, Snail (0.76-fold, $n=8)$ and vimentin (0.72-fold, $n=8)$ were decreased, while E-cadherin (0.98-fold, $n=8)$, Slug (1.12fold, $n=8)$, fibronectin 1 (1.01-fold, $n=8)$ and Twist (1.03-fold, $n=8)$ were not significantly different

Table 4 Altered expression of EMT-related genes

\begin{tabular}{|c|c|c|c|}
\hline Gene & $\begin{array}{l}\text { Fold cl } \\
(n=8\end{array}$ & & Functional grouping \\
\hline BMP7 & 2.77 & Up & $\begin{array}{l}\text { Differentiation and development } \\
\text { Cell growth and proliferation } \\
\text { Extracellular matrix and cell adhesion }\end{array}$ \\
\hline FGFBP1 & 10.64 & Up & $\begin{array}{l}\text { Genes down-regulated during EMT } \\
\text { Cell growth and proliferation }\end{array}$ \\
\hline ITGA5 & 0.45 & Down & Extracellular matrix and cell adhesion \\
\hline KRT19 & 1.67 & Up & Genes down-regulated during EMT \\
\hline MAP1B & 0.41 & Down & Cytoskeleton \\
\hline MMP3 & 0.23 & Down & $\begin{array}{l}\text { Genes up-regulated during EMT } \\
\text { Extracellular matrix and cell adhesion }\end{array}$ \\
\hline MMP9 & 2.20 & Up & $\begin{array}{l}\text { Genes up-regulated during EMT } \\
\text { Extracellular matrix and cell adhesion }\end{array}$ \\
\hline MSN & 2.20 & Up & $\begin{array}{l}\text { Genes up-regulated during EMT } \\
\text { Migration and motility }\end{array}$ \\
\hline MST1R & 1.68 & Up & $\begin{array}{l}\text { Genes down-regulated during EMT } \\
\text { Differentiation and development } \\
\text { Cell growth and proliferation } \\
\text { Migration and motility }\end{array}$ \\
\hline PTP4A1 & 0.49 & Down & Differentiation and development \\
\hline SNAI3 & 1.83 & Up & $\begin{array}{l}\text { Genes up-regulated during EMT } \\
\text { Transcription factors }\end{array}$ \\
\hline SPP1 & 4.82 & Up & $\begin{array}{l}\text { Genes down-regulated during EMT } \\
\text { Extracellular matrix and cell adhesion }\end{array}$ \\
\hline ZEB2 & 0.56 & Down & Transcription factors \\
\hline
\end{tabular}

(Fig. 1b). Compared to healthy inferior turbinates (Fig. 1c), nasal polyps exhibited a higher expression of E-cadherin (3.52-fold, $n=8$ ), N-cadherin (3.72-fold, $n=8$ ), fibronectin 1 (8.91-fold, $n=8)$, vimentin (7.53fold, $n=8$ ), Snail (5.06-fold, $n=8$ ), Slug (9.00-fold, $n=8$ ) and Twist (57.86-fold, $n=8$ ). In the case of Slug $(p<0.05)$ and Twist $(p \leq 0.001)$, the differences were significant increased to those of nasal polyps compared to the inferior turbinate of the same patients (Fig. 1b). Beside these classical EMT markers, further analysis of 77 EMTrelated genes revealed alterations in 13 genes (Table 4). The complete set of EMT-related genes was provided as online supplement (Table S1).

A protein analysis failed to show any statistically significant alterations in E-cadherin, $\mathrm{N}$-cadherin and vimentin expression in nasal polyps compared to inferior turbinates after normalization to GAPDH $(n=8)$. Healthy inferior turbinates showed a lower expression of E-cadherin and vimentin, while $\mathrm{N}$-cadherin could not be detected here $(n=5)$ (Fig. 2).

\section{TGF-ß1 Expression in Tissue of Native Polyps and Inferior Turbinates}

The expression of major components of the TGF- $\beta 1$ signaling pathway was analyzed using qPCR. The mRNA levels of TGF- $\beta 1$, TGF- $\beta 2$, TGF- $\beta 3$, Smad2, Smad 3 and Smad7 showed no significant difference in nasal polyps compared to inferior turbinates. Merely TGF- $\beta 1$ indicated a tendency towards an increased expression (1.53-fold, $n=8$ ) in nasal polyps (Fig. 3a). Compared to healthy inferior turbinates, nasal polyps exhibited a higher expression of TGF- $\beta 1$ (6.80fold, $n=8$ ), TGF- $\beta 2$ (4.14-fold, $n=8$ ), TGF- $\beta 3$ (9.00fold, $n=8$ ), Smad2 (4.65-fold, $n=8$ ), Smad3 (15.48-fold, $n=8)$ and Smad7 (11.64-fold, $n=8)$. In case of TGF- $\beta 1$ $(p<0.05)$ and Smad3 $(p \leq 0.001)$, these differences were significant (Fig. 3b).



Fig. 2 Western blotting exhibited no significant alteration of E-cadherin, N-cadherin and vimentin expression in nasal polyps (P) compared to inferior turbinates (IT) of CRS patients $(n=8)$. Healthy inferior turbinates (hIT) showed a lower expression of
E-cadherin and vimentin, while $\mathrm{N}$-cadherin could not be detected here $(n=5)$. Statistical significance was assessed by Wilcoxon matchedpairs signed rank test 
Fig. 3 a The major components of the TGF- $\beta 1$ signaling pathway showed no significant alterations in gene expression between nasal polyps and inferior turbinates $(n=8)$. Only TGF- $\beta 1$ indicated a tendency of increased expression (1.53-fold). b Scatter plot of the major components of the TGF- $\beta 1$ signaling pathway in nasal polyps (NP) compared to healthy inferior turbinates (hIT) $(n=8)$. Nasal polyps exhibited a higher expression of TGF- $\beta 1$ (6.80-fold, $n=8)$, TGF- $\beta 2$ (4.14-fold, $n=8$ ), TGF- $\beta 3$ (9.00-fold, $n=8$ ), Smad2 (4.65-fold, $n=8$ ), Smad3 (15.48-fold, $n=8$ ) and Smad7 (11.64-fold, $n=8$ ) when compared to hIT. TGF- $\beta 1$ and Smad3 expression was significantly higher in nasal polyps compared to hIT $(p<0.05$ and $p \leq 0.001$, $n=8$ ) than compared to the inferior turbinate of the same patients (a). Statistical significance was assessed by Wilcoxon matched-pairs signed rank test. c At the protein level, TGF- $\beta 1$ showed a trend towards elevated levels in nasal polyp (NP) tissue from CRSwNP $(n=6)$, compared to inferior turbinate (IT) tissue from CRSwNP $(n=3)$. However this increase was not statistically significant ( $p=0.75)$ according to Wilcoxon matched-pairs signed rank test
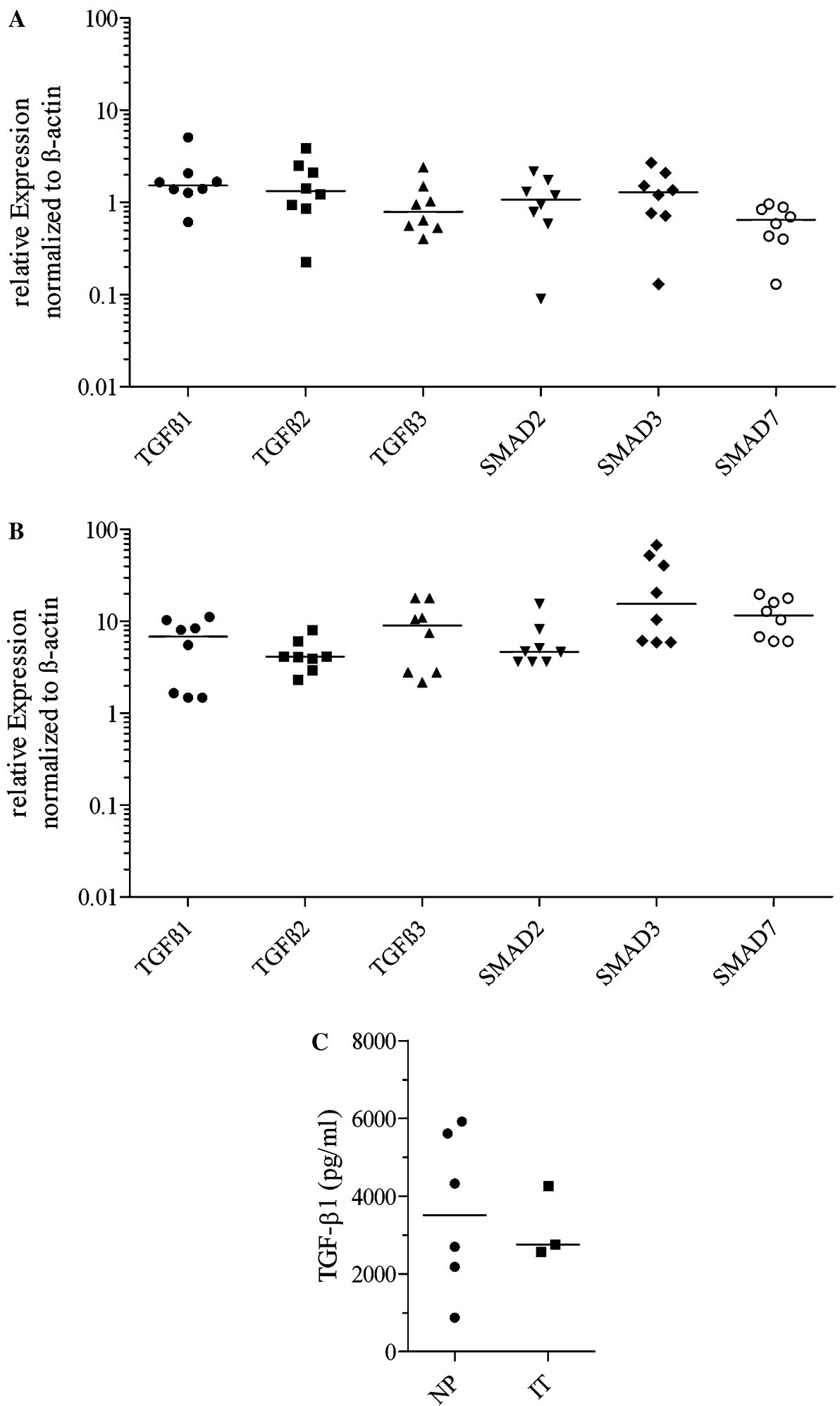

To confirm this observation at the protein level, we prepared lysates of nasal polyp and inferior turbinate tissues and measured the concentration of TGF- $\beta 1$ using ELISA. Although not statistically significant, TGF- $\beta 1$ protein showed a trend towards elevated levels in nasal polyp tissue from CRSwNP ( $n=6$, median expression $3512.97 \mathrm{pg} / \mathrm{ml}$, range $879.62-5916.33 \mathrm{pg} / \mathrm{ml}$ ) compared to inferior turbinate tissue from CRSwNP $(n=3$, median expression $2763.41 \mathrm{pg} / \mathrm{ml}$, range $2577.22-4263.90 \mathrm{pg} / \mathrm{ml}$; Fig. 3c). 


\section{Induction of EMT in NEC}

Upon TGF- $\beta 1$ or EGF treatment, primary NEC of inferior turbinates and nasal polyps displayed a considerable inhibition of cell proliferation and alterations in cell morphology $(n=3)$, changing from the characteristic cobblestone-like growth pattern of differentiated epithelial cells to a scattered distribution with cells possessing a fibroblast-like phenotype after $48 \mathrm{~h}$ of treatment (Fig. 4). To analyze whether these morphological changes are indicative of EMT, we investigated expression and subcellular localization of E-cadherin. Results showed that cells experienced both loss of expression and translocation of this protein. In addition, we noted in TGF- $\beta 1$ and EGFtreated cells a loss of cell-to-cell contacts and an asymmetric morphology, while control cells maintained the typical epithelial cobblestone pattern (Fig. 4). Together, this suggested that primary NEC of inferior turbinates and nasal polyps had underwent EMT in response to both growth factors.

Next, we analyzed the gene expression profiles of EMT markers in response to stimulation with either TGF- $\beta 1$ or EGF in NEC of nasal polyps and inferior turbinates $(n=3)$, at different time points $(6,12$ and $24 \mathrm{~h})$. TGF- $\beta 1$ reduced expression of E-cadherin in nasal polyps (0.47fold) and inferior turbinates (0.62-fold; Fig. 5a) after $24 \mathrm{~h}$. Furthermore, TGF- $\beta 1$ induced expression of $\mathrm{N}$-cadherin in nasal polyps (6.12-fold) and inferior turbinates (5.77-fold; Fig. 5b), but only in nasal polyps Snail (7.88-fold; Fig. 5c), Twist (1.62-fold; Fig. 5e) and fibronectin 1 (2.55-fold; Fig. 5f) were also induced after $24 \mathrm{~h}$. In inferior turbinates, TGF- $\beta 1$ treatment induced expression of multiple mesenchymal markers after 12 and $24 \mathrm{~h}$, including Snail (consistently up-regulated 2.57- to 2.70-fold; Fig. 5c), Twist (1.94-fold, $12 \mathrm{~h}$; Fig. 5e), fibronectin 1 (2.80-fold, 12 h; Fig. 5f) and vimentin (1.52-fold, 24 h; Fig. 5g). Slug
Fig. 4 TGF- $\beta 1$ and EGF stimulation of $1 \times 10^{5} \mathrm{NEC}$ derived from nasal polyps and inferior turbinates. Phalloidin staining was used to evaluate cell morphology and DAPI staining for visualization of cell nuclei. For changes in morphology corresponding to EMT, we analyzed expression of E-cadherin after $48 \mathrm{~h}$. Note the morphological changes, the loss of cell-to-cell contacts, the asymmetrical morphology and the loss and translocation of E-cadherin $(n=3)$

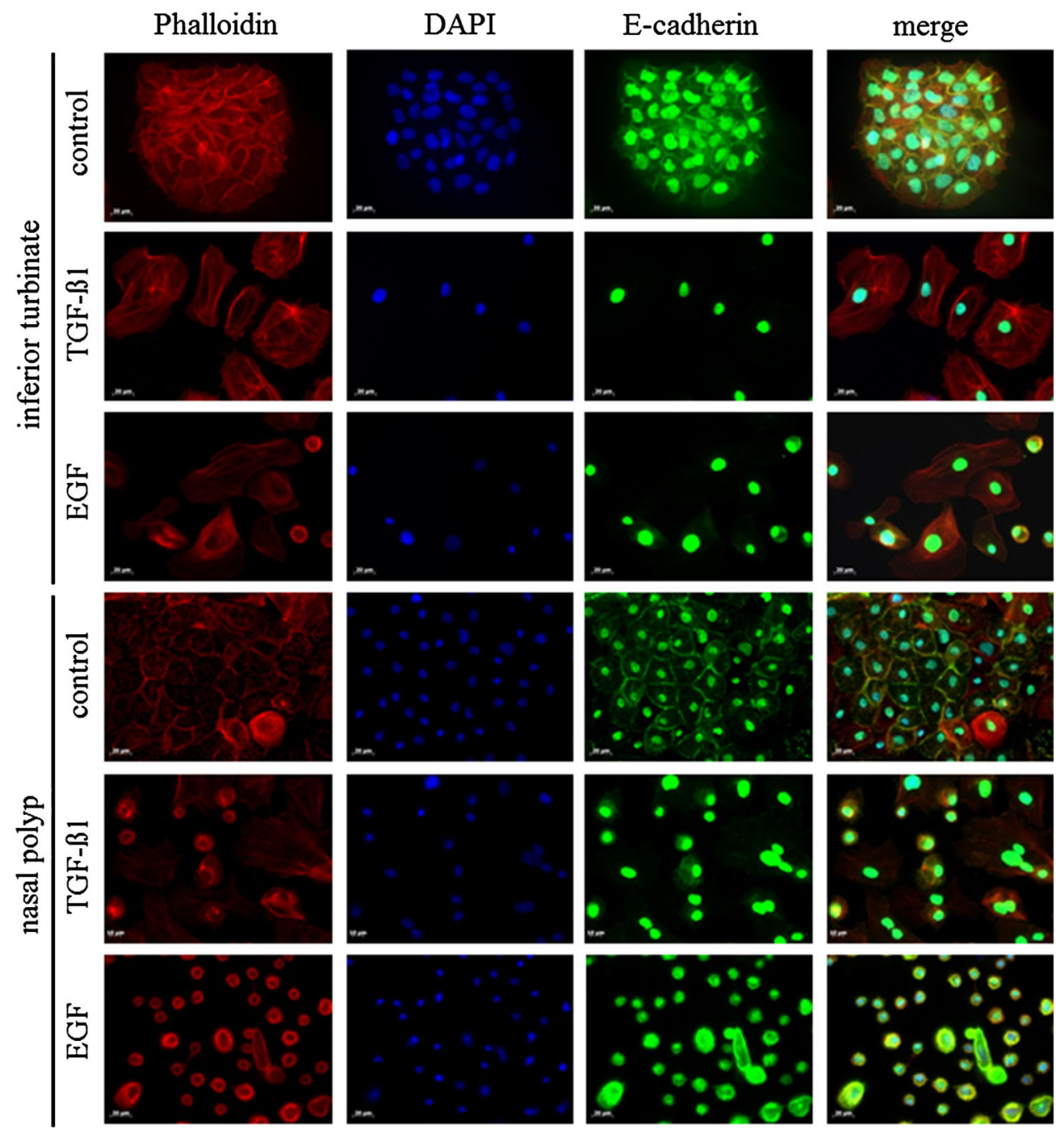



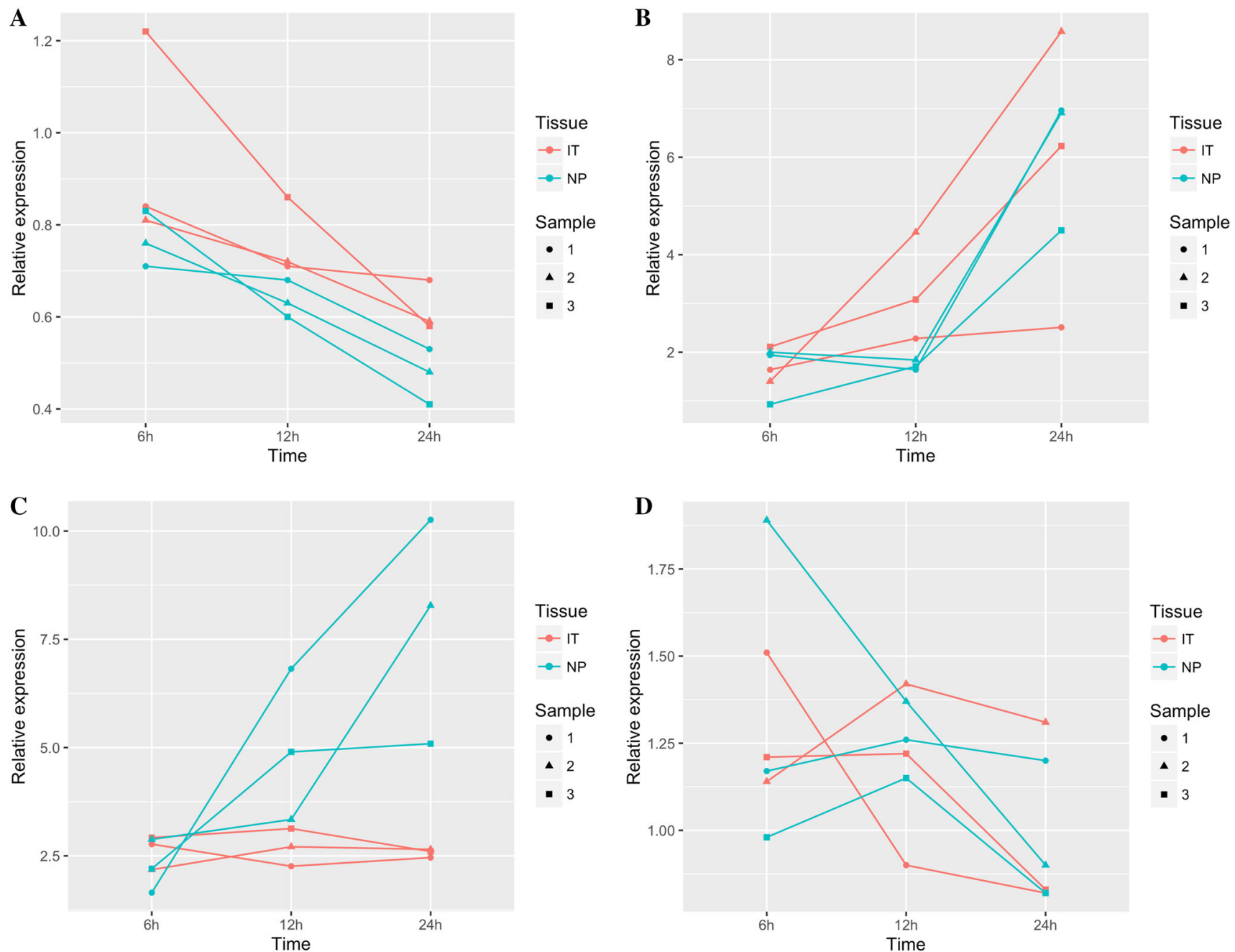

Fig. 5 Gene expression profiles of EMT markers in response to a 24 h-treatment with TGF- $\beta 1$ in $7.5 \times 10^{4} \mathrm{NEC}$ of nasal polyps and inferior turbinates $(n=3)$. In nasal polyps, TGF- $\beta 1$ reduced expression of E-cadherin (0.47-fold, a) and induced N-cadherin (6.12-fold, b), Snail (7.88-fold, c), Twist (1.62-fold, e) and fibronectin 1 (2.55-

expression remained unaltered in both nasal polyps and inferior turbinates (Fig. 5d). Upon a comparison of NEC derived from nasal polyps with those derived from inferior turbinates, we observed alterations after TGF- $\beta 1$ stimulation. The expression of Snail (Fig. 5c) and vimentin (Fig. $5 \mathrm{~g}$ ) increased after 12 and $24 \mathrm{~h}$, and after 6 and $12 \mathrm{~h}$, respectively, in NEC from nasal polyps compared to NEC from inferior turbinates. Twist (Fig. 5e) and fibronectin 1 (Fig. 5f) expression was increased after $12 \mathrm{~h}$ in NEC from inferior turbinates when compared to NEC from nasal polyps. Interestingly, both NEC from nasal polyps and those from inferior turbinates responded equally with E-cadherin (down-regulation) and $\mathrm{N}$-cadherin (up-regulation) gene expression after TGF- $\beta 1$ treatment. Next, we investigated significant effects over time (time effect $=p \_$time), between NEC from nasal polyps and

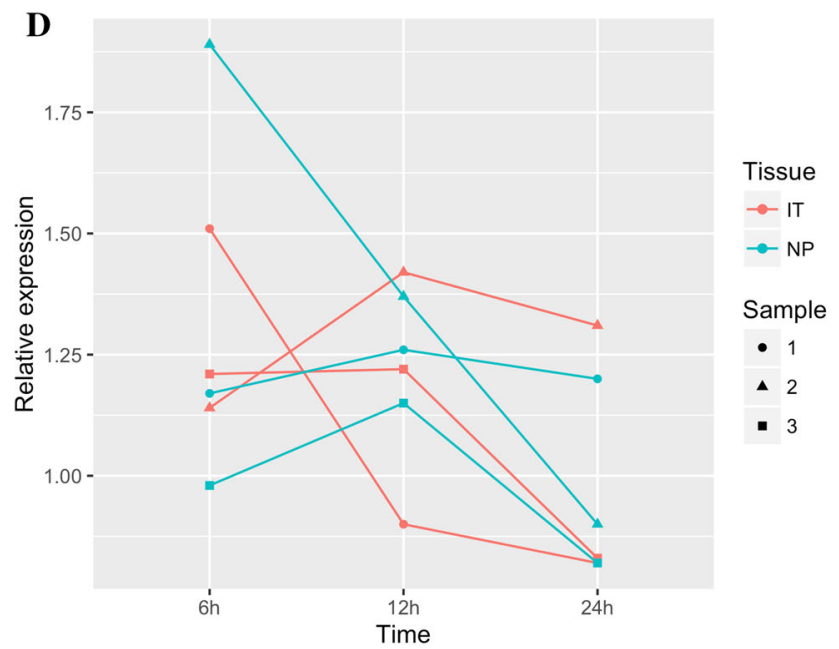

fold, f). In inferior turbinates, TGF- $\beta 1$ reduced expression of E-cadherin (0.62-fold, a) and induced expression of $\mathrm{N}$-cadherin (5.77-fold, b), Snail (2.57- to 2.70-fold, c), Twist (1.94-fold, $12 \mathrm{~h}, \mathbf{e}$ ), fibronectin 1 (2.80-fold, $12 \mathrm{~h}, \mathbf{f})$ and vimentin (1.52-fold, $24 \mathrm{~h}, \mathbf{g})$. Statistical significance was assessed by two-way ANOVA

inferior turbinates over all time points (tissue effect $=p_{-}$tissue) and whether there were difference between time points as a function of tissue type (interaction effect $=p \_$ie) $($Table 5). After TGF- $\beta 1$ stimulation, gene expression of E-cadherin $(p=0.0011), \quad \mathrm{N}$-cadherin $(p=0.0008)$, Snail $(p=0.0115)$ and Twist $(p=0.0018)$ was significantly altered over time. A comparison between NEC from nasal polyps and inferior turbinates showed significant differences for E-cadherin $(p=0.0114)$, Snail $(p=0.0023)$ and vimentin $(p=0.0199)$. Snail $(p=$ $0.0102)$, Twist $(p=0.0001)$ and vimentin $(p=0.0477)$ also exhibited significant differences between time points in dependence of tissue type.

EGF stimulation of NEC from nasal polyps induced the expression of Snail (1.93-fold; Fig. 6c), Slug (2.33-fold; Fig. 6d) and vimentin (2.41-fold; Fig. 6g) after 12 h, but 

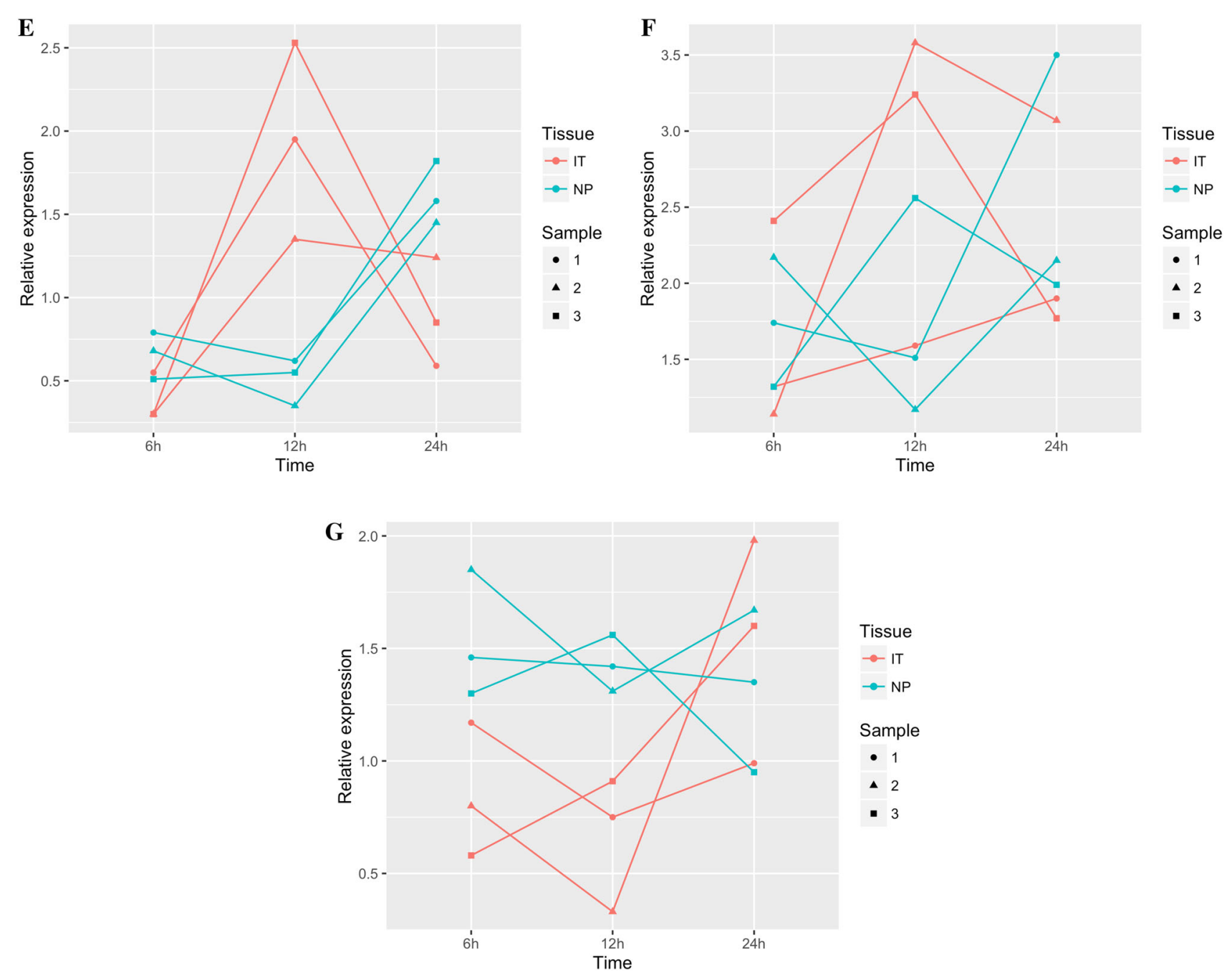

Fig. 5 continued

their expression was declined by $24 \mathrm{~h}$. Additionally, Twist (3.45-fold; Fig. 6e) was increased after $24 \mathrm{~h}$. No differences were detected for E-cadherin, $\mathrm{N}$-cadherin and fibronectin 1 (Fig. 6a, b, f). In inferior turbinates, EGF stimulation induced expression of Twist (4.14-fold; Fig. 6e) after 6 h, but subsequently declined. Fibronectin 1 and vimentin expression was increased after $12 \mathrm{~h}(1.58-$ fold; Fig. 6f) and after $24 \mathrm{~h}$ (1.54-fold; Fig. 6g), respectively. No differences were detected for E-cadherin, $\mathrm{N}$-cadherin, Snail and Slug (Fig. 6a-d). The comparison of NEC from nasal polyps and inferior turbinates revealed increased expression of Snail (Fig. 6c), Slug (Fig. 6d) and vimentin (Fig. $6 \mathrm{~g}$ ) in NEC from nasal polyps after $12 \mathrm{~h}$. Interestingly, Twist (Fig. 6e) expression was reciprocally regulated in NEC derived from nasal polyps and those from inferior turbinates after EGF treatment. After EGF stimulation, gene expression of Slug $(p=0.0026)$, fibronectin 1 $(p=0.0002)$ and vimentin $(p=0.0033)$ was significantly altered over time. When NEC from nasal polyps and inferior turbinates were compared, Slug $(p=0.0113)$ and vimentin $(p=0.0137)$ showed significant differences. N-cadherin $(p=0.0351), \quad$ Slug $(p=0.0133), \quad$ Twist $(p=0.0002)$ and vimentin $(p=0.0027)$ also were significantly different between time points as a function of tissue type.

\section{NEC Respond to TGF- $\beta 1$ with Increased Migratory Activity}

Cells undergoing EMT are known to have a higher potential for cell motility as a consequence of cytoskeletal rearrangements. Hence, we hypothesized that NEC which have undergone EMT exhibit an enhanced migratory activity in response to TGF- $\beta 1$ and EGF treatment. In a representative experiment $(n=3), \quad$ a significantly increased migration was observed in NEC from nasal 
Table 5 Statistical analysis of NEC gene expression after stimulation

\begin{tabular}{|c|c|c|c|c|}
\hline Stimulant & Gene & p_time & $p \_$tissue & $p \_$ie \\
\hline TGF- $\beta 1$ & E-cadherin & 0.0011 & 0.0114 & 0.8740 \\
\hline TGF- $\beta 1$ & $\mathrm{~N}$-cadherin & 0.0008 & 0.5320 & 0.5000 \\
\hline TGF- $\beta 1$ & Snail & 0.0115 & 0.0023 & 0.0102 \\
\hline TGF- $\beta 1$ & Slug & 0.1110 & 0.7330 & 0.9460 \\
\hline TGF- $\beta 1$ & Twist & 0.0018 & 0.3280 & 0.0001 \\
\hline TGF- $\beta 1$ & Fibronectin 1 & 0.2640 & 0.5670 & 0.2860 \\
\hline TGF- $\beta 1$ & Vimentin & 0.1800 & 0.0199 & 0.0477 \\
\hline EGF & E-cadherin & 0.1040 & 0.7070 & 0.2670 \\
\hline EGF & $\mathrm{N}$-cadherin & 0.9690 & 0.4670 & 0.0351 \\
\hline EGF & Snail & 0.1950 & 0.0997 & 0.2430 \\
\hline EGF & Slug & 0.0026 & 0.0113 & 0.0133 \\
\hline EGF & Twist & 0.2100 & 0.0562 & 0.0002 \\
\hline EGF & Fibronectin 1 & 0.0002 & 0.6210 & 0.1830 \\
\hline EGF & Vimentin & 0.0033 & 0.0137 & 0.0027 \\
\hline
\end{tabular}

Statistical significant values were highlighted in bold

$p \_$time $p$ value of time effects, $p \_t i s s u e ~ p$ value of tissue effects, $p \_i e p$ value of interaction effects

polyps after TGF- $\beta 1$ treatment (slope 0.042 , time range $5-15 \mathrm{~h}, p \leq 0.05)$ but not in non-stimulated NEC from nasal polyps (slope 0.001 , time range $5-15 \mathrm{~h}$; Fig. 7a). NEC of inferior turbinates did not respond to TGF- $\beta 1$ treatment with a significant increase in migration (slope 0.0116 vs. 0.0065 , time range $5-15$ h; Fig. $7 b$ ). In contrast, EGF stimulation induced a slight increase in migration in NEC from nasal polyps (slope 0.02 , time range $5-15 \mathrm{~h}$ ) when compared to non-stimulated NEC (slope 0.001, time range 5-15 h; Fig. 7a), while cell indices from inferior turbinates were not significantly different from non-stimulated controls (slope 0.0099 vs. 0.0065, time range 5-15 h) or exhibited an even lower activity (Fig. 7b).

To exclude the possibility that a higher proliferation rate was responsible for the observed differences in migratory activity after TGF- $\beta 1$ or EGF treatment, we employed the MTT assay $(n=3)$. Since we found no statistically significant differences in the activity of cellular enzymes in NEC from nasal polyps and inferior turbinate after TGF- $\beta 1$ or EGF treatment in the first $24 \mathrm{~h}$ (Fig. 8a/b), the observed differences in the migratory activities after TGF- $\beta 1$ or EGF treatment are unlikely to reflect differences in proliferation. These data uncovered an important functional difference between NEC from nasal polyps and those from inferior turbinates in growth factor-induced cell motility and, in addition, revealed that TGF- $\beta 1$ and EGF differ in their capacity to elicit a migratory response in these cells.

\section{Discussion}

During EMT, the highly differentiated and specialized epithelial cells may lose their epithelial phenotype and convert to a mesenchymal cell type. The loss of epithelial and acquisition of mesenchymal characteristics is well described as part of the oncogenic transformation process. In epithelial tumors, this transition represents a crucial step in tumor invasion and metastasis formation (Nawshad et al. 2005; Thiery et al. 2009; Willis and Borok 2007). It has been suggested that epithelial cells may possess phenotypic plasticity and are able to undergo more radical changes that eventually lead to a mesenchymal phenotype (Kalluri and Neilson 2003; Willis et al. 2005; Zavadil and Bottinger 2005).

Tissue remodeling is a typical response to chronic inflammation and provokes alterations in the structural organization of tissues, and EMT is a crucial mechanism involved in tissue remodeling (Thiery et al. 2009). Here we show for the first time that NECs from nasal polyps and inferior turbinates were able to undergo an EMT-like process, based on morphological alterations including loss of cell-cell contact and the expression of mesenchymal markers. Furthermore, we show that markers of EMT can be induced in NEC from inferior turbinates and those from nasal polyps in vitro in a time-dependent manner, and that both NEC types exhibit a different marker profile 

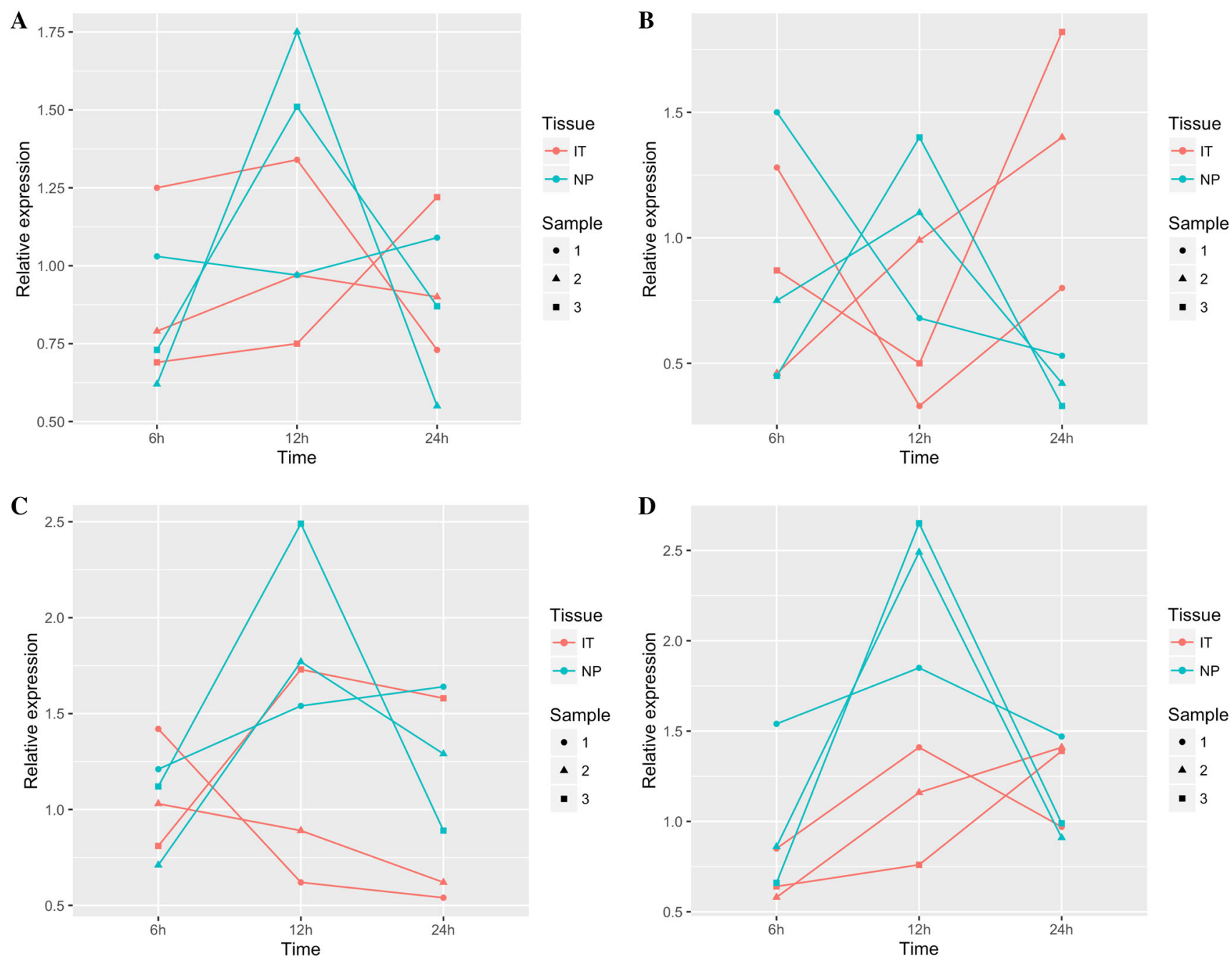

Fig. 6 Gene expression profiles of EMT markers in response to a $24 \mathrm{~h}$-treatment with EGF in $7.5 \times 10^{4} \mathrm{NEC}$ of nasal polyps and inferior turbinates $(n=3)$. EGF induced the expression of Snail (1.93-fold, c), Slug (2.33-fold, d) and vimentin (2.41-fold, g) after $12 \mathrm{~h}$ and Twist (3.45-fold, e) after $24 \mathrm{~h}$ in NEC from nasal polyps. In

according to the tissue of origin and the nature of the EMTinducing agent. Both TGF- $\beta 1$ and EGF have been reported to induce EMT (Dennler et al. 2002; Hackett et al. 2009; Miettinen et al. 1994; Nawshad et al. 2005; Thiery et al. 2009 ) in a variety of benign and malignant epithelial cells (Ahmed et al. 2006; Cheng et al. 2012; Colomiere et al. 2009). Although statistical significance was not reached (which was likely due to the low sample number), TGF- $\beta 1$ was found to be elevated at both the mRNA and protein level in nasal polyp tissue compared to inferior turbinate tissue from CRSwNP. We used TGF- $\beta 1$, a known airway modulating agent, and EGF since both factors are established inducers of EMT. Earlier studies on EMT in airway epithelial cells (Hackett et al. 2009; Molloy et al. 2008; Ward et al. 2005) have shown a reduction in E-cadherin inferior turbinates, EGF stimulation induced the expression of Twist (4.14-fold, e) after $6 \mathrm{~h}$, fibronectin 1 after $12 \mathrm{~h}$ (1.58-fold, f) and vimentin (1.54-fold, g) after $24 \mathrm{~h}$. Statistical significance was assessed by two-way ANOVA

expression after stimulation with TGF- $\beta 1$. In the present study, exposure of NEC from nasal polyps and inferior turbinates to TGF- $\beta 1$ led to EMT, as assessed by expression of the respective markers and cellular morphology. Specifically, we observed a significant reduction in E-cadherin expression and transcriptional activity of mesenchymal EMT markers. Our data suggest that TGF- $\beta 1$ mediated EMT in NEC occurred in distinctive phases in inferior turbinates as well as in nasal polyps and was differently regulated. In epithelial cells from inferior turbinates, E-cadherin and $\mathrm{N}$-cadherin expression was inversely regulated just like in epithelial cells from nasal polyps. This change from E-cadherin to N-cadherin expression was known as "cadherin switch" and was used to follow the EMT process in embryogenesis and tumor 

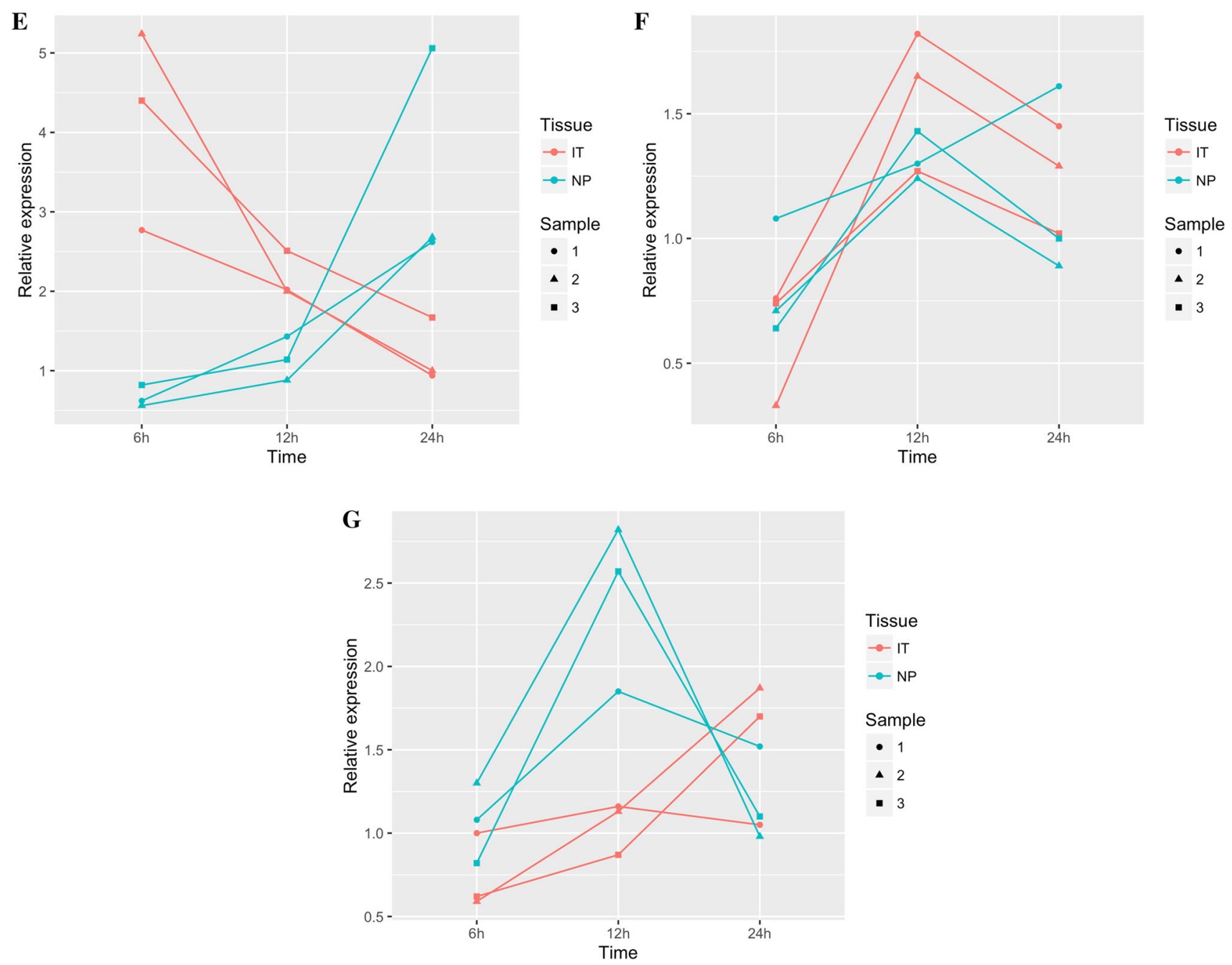

Fig. 6 continued

progression (Zeisberg and Neilson 2009). Initially, both tissues did not differ in their mRNA content of mesenchymal EMT markers. Interestingly, NEC of interior turbinates exhibited a rapid induction of gene expression of Twist and fibronectin 1 after $12 \mathrm{~h}$. However, expression decreased after $24 \mathrm{~h}$, while in nasal polyps N-cadherin and Snail increased after $24 \mathrm{~h}$, suggesting different regulation of these markers in nasal polyps and inferior turbinates of CRS patients.

EGF stimulation was able to induce EMT in NEC of nasal polyps by induction of mesenchymal markers and E-cadherin translocation. Cheng et al. (2012) showed that EGF treatment induced a switch from E-cadherin to $\mathrm{N}$-cadherin expression in SBOT cells and it is known that the ERK1/2, p38 MAPK and PI3K/Akt pathways were involved in EGF-induced EMT (Ahmed et al. 2006; Cheng et al. 2010). Recently, we have shown that EGFR signaling is actively involved in the pathogenesis of nasal polyps (Linke et al. 2013a, b). We also demonstrated that EGFR signaling induced EMT in NEC, however, the identity of the signal intermediates involved remains to be determined. Another study by Shin et al. (2012) reported HIF1- $\alpha$ as an EMT inducer in nasal polyps. Human NEC undergo EMT during hypoxia, which was mediated by HIF1- $\alpha$ and phospho-Smad3. Different EMT markers (E-cadherin, $\alpha$ SMA, $\beta$-catenin, vimentin, Twist) were screened, but HIF1- $\alpha$ alone was not sufficient for EMT induction. In the present study, our microarray data revealed no up-regulation of HIF1- $\alpha$ (unpublished observation). It could be shown that not only the pathogenesis of nasal polyps but also that of COPD was linked to EMT (Gohy et al. 2014; Milara et al. 2013; Sohal et al. 2011).

Recently, Hupin et al. (2014) observed features of EMT in CRSwNP and CRSsNP patients. In a cohort of 45 patients, including 11 patients with CRSsNP, 11 patients with CRSwNP, 10 patients with allergic rhinitis and 13 control patients, the expression of E-cadherin, high molecular weight cytokeratins and cytokeratin 5 as 
Fig. 7 Cell migration assay of $2 \times 10^{4} \mathrm{NEC}(n=3)$. a A strongly and significantly increased migration was observed after TGF- $\beta 1(+\mathrm{T})$ treatment (green curve) in NEC of nasal polyp (NEC NP) compared to unstimulated NEC (red curve, slope 0.042 vs. $0.001, p \leq 0.05)$. EGF stimulation $(+\mathrm{E})$ induced a slight increase in migration (blue curve, slope 0.02). b No increased migration was seen in NEC of inferior turbinates (NEC IT) when unstimulated NEC (red curve) were compared with TGF- $\beta 1$ (green curve) or EGF (blue curve) treated cells (slope 0.0065 vs. 0.0116 vs. 0.0099 ). This figure is a representative example of several experiments $(n=3)$ and the error bars represent variability between replicates. Statistical significance was assessed by Wilcoxon matched-pairs signed rank test
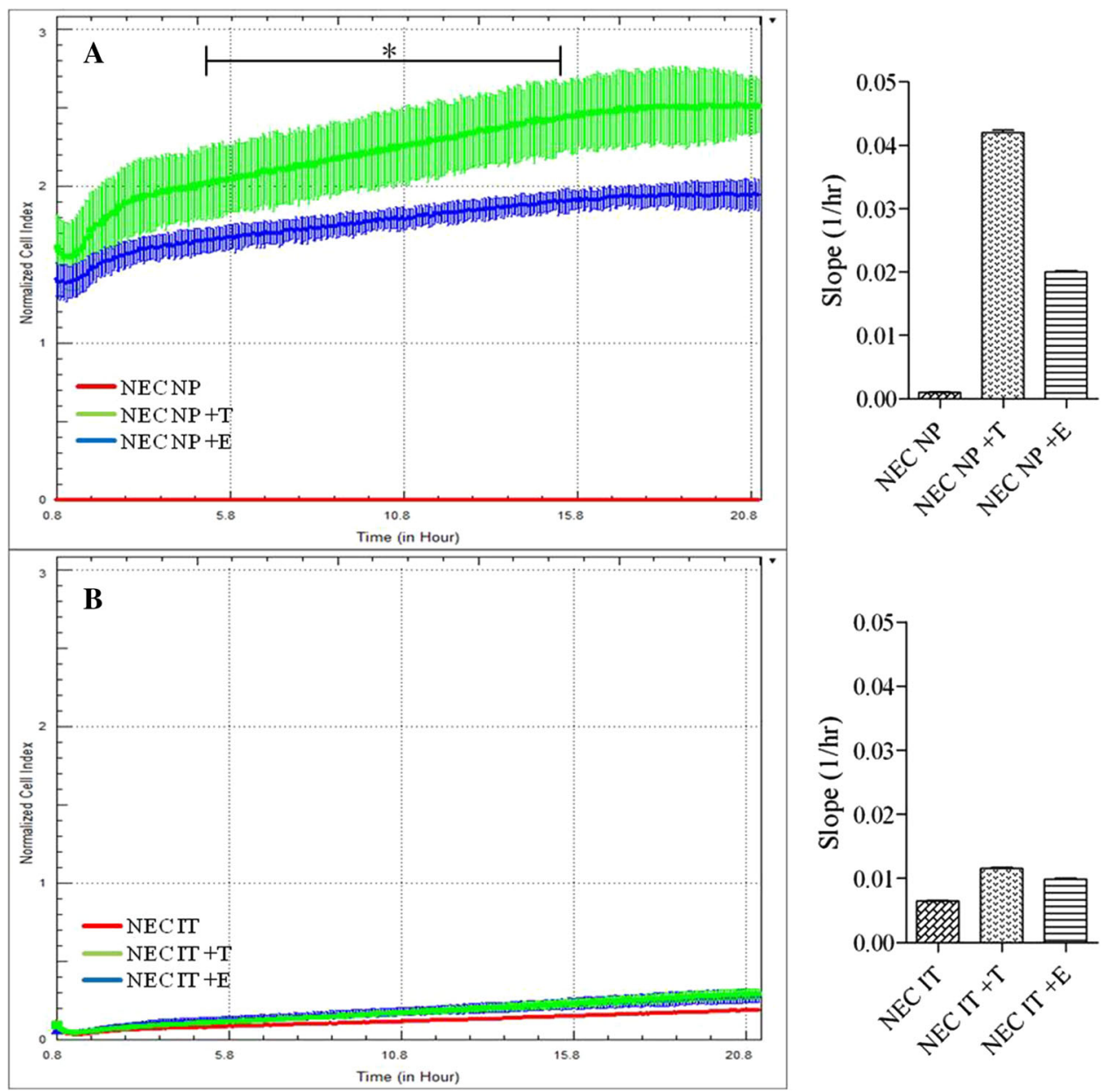

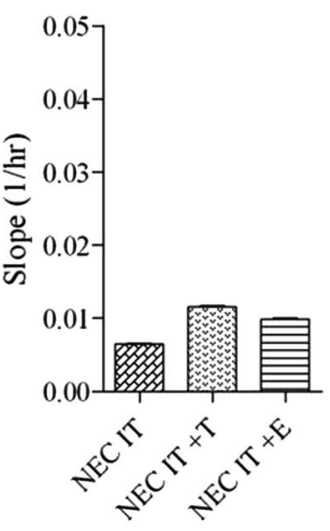

epithelial markers and vimentin as mesenchymal markers were determined in biopsies from ethmoidal mucosa (CRSsNP and CRSwNP) and inferior turbinates (controls and allergic rhinitis). Additional lineage markers for ciliated cells ( $\beta$-tubulin IV), goblet cells (MUC5AC) and basal cells (p63) were analyzed. A decreased E-cadherin and cytokeratin expression along with increased vimentin expression was observed in epithelial cells of CRSsNP and CRSwNP, while this dedifferentiation was not related to changes in lineage specification. These authors concluded that changes to a more mesenchymal phenotype occurred in CRSsNP and CRSwNP, but due to the only limited analysis of EMT-related markers prohibited definite conclusions as to whether CRS underwent EMT. To obtain a deeper insight into the pathogenesis of nasal polyps in CRS patients, we determined expression of up to 77 different EMT-related markers in tissue from nasal polyps and inferior turbinates of $30 \mathrm{CRSwNP}$ patients. The inferior turbinate of the same patient represents a good internal control due to the fact that it is not affected by nasal polyp growth and shares the same chronic inflammatory conditions as nasal polyps. However, we did not find significant differences in expression of E-cadherin, N-cadherin, vimentin, fibronectin 1, Snail, Slug and Twist between nasal polyps and inferior turbinates but their expression was significantly higher than in inferior turbinates from healthy individuals. When our marker analysis was extended to another set of 77 EMTassociated genes, we identified 13 genes, which were differentially expressed in nasal polyps compared to inferior turbinates. Functional gene grouping was used to evaluate and enhance the biological interpretation. Unfortunately, within these 13 differentially expressed genes, a clear EMT profile was not detected. On the one hand, genes which were usually down-regulated during EMT were found to be up-regulated, like fibroblast growth factor binding protein 1, keratin 19, macrophagestimulating protein receptor and secreted phosphoprotein 1. On the other hand, genes, which are known to be upregulated during EMT were actually found up-regulated like matrix metalloproteinase 9 (MMP)9, moesin and Snail family zinc finger 3, but not MMP3. These results suggest that nasal polyp cells arrest in intermediate stages of EMT, when epithelial markers are still expressed but 

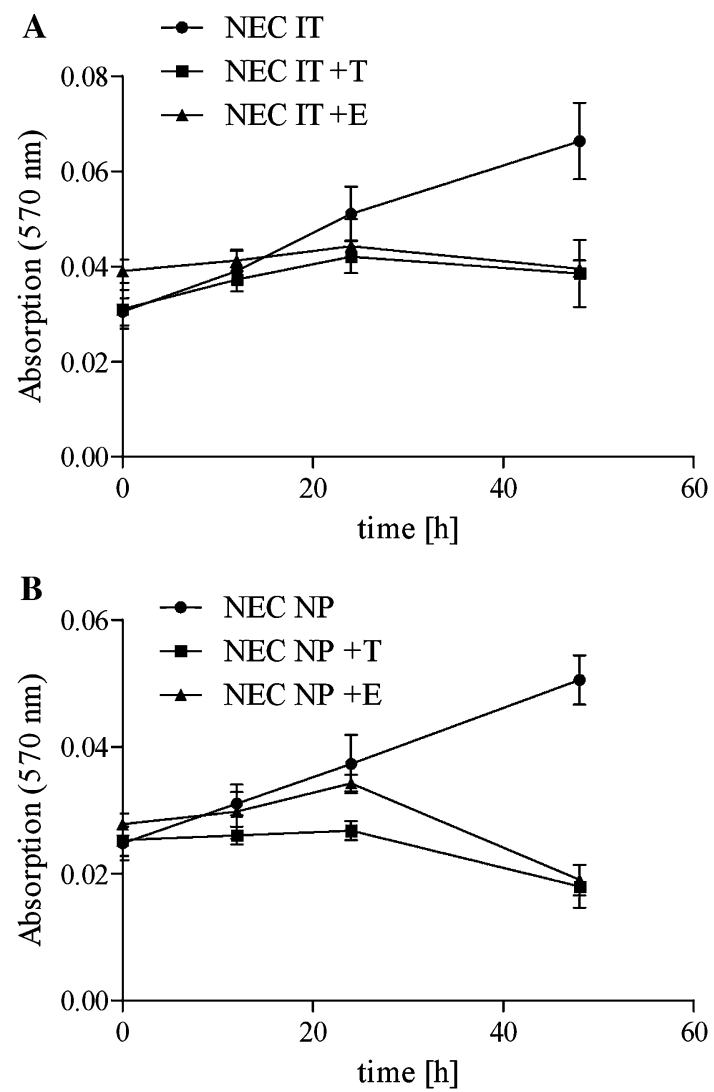

Fig. 8 Metabolic activity of $5 \times 10^{3}$ NEC $(n=3)$. NEC from inferior turbinates (a) and nasal polyps (b) were stimulated with either TGF- $\beta 1$ or EGF. Metabolic activity reflecting the proliferative potential of the cells was measured with MTT assay after 12, 24 and $48 \mathrm{~h}$. This figure is a representative example of several experiments $(n=3)$ and the error bars represent variability between replicates

full expression of new mesenchymal markers have not yet been acquired. The behavior of these cells indicated that epithelial cells under inflammatory stress can increase EMT to a different extent, a phenomenon that has been termed "partial EMT" (Kalluri and Weinberg 2009). Partial EMT has been found to be of great physiological significance in oncology as it is thought to generate cancer cells that are more drug/apoptosis-resistant, and possess a higher potential for tumor-initiation and metastatic dissemination than cancer cells with a complete EMT phenotype (Jolly et al. 2015).

Even if NEC from nasal polyps and those from inferior turbinates share the same chronic inflammatory conditions, they responded differently to TGF- $\beta$ and EGF. The strong migratory response of NEC from nasal polyps suggests that these cells differ from those of inferior turbinates in the activity of genes that control cell motility. These genes may differ since TGF- $\beta 1$ and EGF displayed different capacities in eliciting a migratory response in these cells. This was also seen in expression of EMT markers after
TGF- $\beta 1$ or EGF-induced EMT. NEC from nasal polyps and inferior turbinates responded with gene-specific differences to TGF- $\beta 1$ or EGF treatment. However, the most important difference was observed in Twist expression. Twist was significantly up-regulated in NEC of nasal polyps after TGF- $\beta 1$ or EGF treatment, but not in NEC of inferior turbinates. Rather, we found a significant decrease of Twist expression in NEC of inferior turbinates. The differential expression of Snail, Slug and/or Twist may explain the different migratory responses of these cells since all three proteins have been shown to be involved in the regulation of cell motility (Chen et al. 2014; Leber and Efferth 2009; Uygur and $\mathrm{Wu} 2011$ ).

In summary, nasal polyp tissue exhibited expression of both epithelial and mesenchymal markers. Our data indicate that partial EMT occurs during pathogenesis of nasal polyps in CRS patients. Furthermore, we showed for the first time that epithelial cells from both nasal polyps and inferior turbinates were susceptible to undergo an EMTlike process in vitro in response to appropriate stimuli (growth factors). This was evident from a loss of E-cadherin, gain of various mesenchymal markers and, in epithelial cells of nasal polyps only, an increase in cell migration. However, further studies are necessary to validate our hypothesis that EMT is a key mechanism in the pathogenesis of nasal polyps in CRS and, if so, whether its therapeutic suppression could represent a promising strategy in the future.

Acknowledgments We are grateful to all the members of the Department of Otorhinolaryngology for helpful discussions and a stimulating atmosphere. This work was supported by the Cassellamed GmbH \& Co. KG, Köln, Germany, and the Rudolf BartlingStiftung, Hannover, Germany.

\section{Compliance with ethical standards}

Conflict of interest The authors declare that they have no conflict of interests.

Research involving human participants and/or animals All procedures performed in studies involving human participants were in accordance with the ethical standards of the institutional and/or national research committee and with the 1964 Helsinki declaration and its later amendments or comparable ethical standards. This article does not contain any studies with animals performed by any of the authors.

Informed consent Informed consent was obtained from- all individual participants included in the study.

\section{References}

Ahmed N, Maines-Bandiera S, Quinn MA et al (2006) Molecular pathways regulating EGF-induced epithelio-mesenchymal transition in human ovarian surface epithelium. Am J Physiol Cell Physiol 290:C1532-C1542 
Al-Muhsen S, Johnson JR, Hamid Q (2011) Remodeling in asthma. J Allergy Clin Immunol 128:451-462

Chen J, Xu H, Zou X et al (2014) Snail recruits Ring1B to mediate transcriptional repression and cell migration in pancreatic cancer cells. Cancer Res 74:4353-4363

Cheng JC, Klausen C, Leung PC (2010) Hydrogen peroxide mediates EGF-induced down-regulation of E-cadherin expression via $\mathrm{p} 38$ MAPK and snail in human ovarian cancer cells. Mol Endocrinol 24:1569-1580

Cheng JC, Auersperg N, Leung PC (2012) EGF-induced EMT and invasiveness in serous borderline ovarian tumor cells: a possible step in the transition to low-grade serous carcinoma cells? PLoS One 7:e34071

Colomiere M, Ward AC, Riley C et al (2009) Cross talk of signals between EGFR and IL-6R through JAK2/STAT3 mediate epithelial-mesenchymal transition in ovarian carcinomas. Br J Cancer 100:134-144

Dennler S, Goumans MJ, ten Dijke P (2002) Transforming growth factor beta signal transduction. J Leukoc Biol 71:731-740

Fleige S, Pfaffl MW (2006) RNA integrity and the effect on the realtime qRT-PCR performance. Mol Aspects Med 27:126-139

Fokkens WJ, Lund VJ, Mullol J et al (2012) European position paper on rhinosinusitis and nasal polyps 2012. Rhinology 50(Suppl 23):1-298

Gohy ST, Detry BR, Lecocq M et al (2014) Polymeric immunoglobulin receptor down-regulation in chronic obstructive pulmonary disease. Persistence in the cultured epithelium and role of transforming growth factor-beta. Am J Respir Crit Care Med 190:509-521

Hackett TL, Warner SM, Stefanowicz D et al (2009) Induction of epithelial-mesenchymal transition in primary airway epithelial cells from patients with asthma by transforming growth factorbeta 1. Am J Respir Crit Care Med 180:122-133

Hastan D, Fokkens WJ, Bachert C et al (2011) Chronic rhinosinusitis in Europe-an underestimated disease. A GA(2)LEN study. Allergy 66:1216-1223

Hupin C, Gohy S, Bouzin C et al (2014) Features of mesenchymal transition in the airway epithelium from chronic rhinosinusitis. Allergy 69:1540-1549

Jolly MK, Boareto M, Huang B et al (2015) Implications of the hybrid epithelial/mesenchymal phenotype in metastasis. Front Oncol 5:155

Kalluri R, Neilson EG (2003) Epithelial-mesenchymal transition and its implications for fibrosis. J Clin Invest 112:1776-1784

Kalluri R, Weinberg RA (2009) The basics of epithelial-mesenchymal transition. J Clin Invest 119:1420-1428

Kim TH, Lee JY, Lee HM et al (2010) Remodelling of nasal mucosa in mild and severe persistent allergic rhinitis with special reference to the distribution of collagen, proteoglycans, and lymphatic vessels. Clin Exp Allergy 40:1742-1754

Könnecke M, Böscke R, Waldmann A et al (2014) Immune imbalance in nasal polyps of Caucasian chronic rhinosinusitis patients is associated with a downregulation of E-selectin. J Immunol Res 2014:959854

Kupcsik L (2011) Estimation of cell number based on metabolic activity: the MTT reduction assay. Methods Mol Biol 740:13-19

Leber MF, Efferth T (2009) Molecular principles of cancer invasion and metastasis (review). Int J Oncol 34:881-895

Lee JM, Dedhar S, Kalluri R et al (2006) The epithelial-mesenchymal transition: new insights in signaling, development, and disease. J Cell Biol 172:973-981

Linke R, Pries R, Könnecke M et al (2013a) Glycogen synthase kinase 3 in chronic rhinosinusitis: two faces of a single enzyme in one disease. Ann Allergy Asthma Immunol 110:101-106
Linke R, Pries R, Könnecke M et al (2013b) Increased activation and differentiated localization of native and phosphorylated STAT3 in nasal polyps. Int Arch Allergy Immunol 162:290-298

Livak KJ, Schmittgen TD (2001) Analysis of relative gene expression data using real-time quantitative PCR and the 2(-Delta Delta $\mathrm{C}(\mathrm{T}))$ method. Methods 25:402-408

Miettinen PJ, Ebner R, Lopez AR et al (1994) TGF-beta induced transdifferentiation of mammary epithelial cells to mesenchymal cells: involvement of type I receptors. J Cell Biol 127(6 Pt2):2021-2036

Milara J, Peiro T, Serrano A et al (2013) Epithelial to mesenchymal transition is increased in patients with COPD and induced by cigarette smoke. Thorax 68:410-420

Molloy EL, Adams A, Moore JB et al (2008) BMP4 induces an epithelial-mesenchymal transition-like response in adult airway epithelial cells. Growth Factors 26:12-22

Mosmann T (1983) Rapid colorimetric assay for cellular growth and survival: application to proliferation and cytotoxicity assays. J Immunol Methods 65:55-63

Nawshad A, Lagamba D, Polad A et al (2005) Transforming growth factor-beta signaling during epithelial-mesenchymal transformation: implications for embryogenesis and tumor metastasis. Cells Tissues Organs 179:11-23

Rehl RM, Balla AA, Cabay RJ et al (2007) Mucosal remodeling in chronic rhinosinusitis. Am J Rhinol 21:651-657

Shin HW et al (2012) Hypoxia-inducible factor 1 mediates nasal polypogenesis by inducing epithelial-to-mesenchymal transition. Am J Respir Crit Care Med 185:944-954

Sieuwerts AM, Klijn JG, Peters HA et al (1995) The MTT tetrazolium salt assay scrutinized: how to use this assay reliably to measure metabolic activity of cell cultures in vitro for the assessment of growth characteristics, IC50-values and cell survival. Eur J Clin Chem Clin Biochem 33:813-823

Sohal SS, Reid D, Soltani A et al (2011) Evaluation of epithelial mesenchymal transition in patients with chronic obstructive pulmonary disease. Respir Res 12:130

Tan BK, Schleimer RP, Kern RC (2010) Perspectives on the etiology of chronic rhinosinusitis. Curr Opin Otolaryngol Head Neck Surg 18:21-26

Thiery JP, Acloque H, Huang RY et al (2009) Epithelial-mesenchymal transitions in development and disease. Cell 139:871-890

Uygur B, Wu WS (2011) SLUG promotes prostate cancer cell migration and invasion via CXCR4/CXCL12 axis. Mol Cancer 10:139

Van Bruaene N, Bachert C (2011) Tissue remodeling in chronic rhinosinusitis. Curr Opin Allergy Clin Immunol 11:8-11

Ward C, Forrest IA, Murphy DM et al (2005) Phenotype of airway epithelial cells suggests epithelial to mesenchymal cell transition in clinically stable lung transplant recipients. Thorax 60:865-871

Willis BC, Borok Z (2007) TGF-beta-induced EMT: mechanisms and implications for fibrotic lung disease. Am J Physiol Lung Cell Mol Physiol 293:L525-L534

Willis BC, Liebler JM, Luby-Phelps K et al (2005) Induction of epithelial-mesenchymal transition in alveolar epithelial cells by transforming growth factor-beta 1: potential role in idiopathic pulmonary fibrosis. Am J Pathol 166:1321-1332

Zavadil J, Bottinger EP (2005) TGF-beta and epithelial-to-mesenchymal transitions. Oncogene 24:5764-5774

Zeisberg M, Neilson EG (2009) Biomarkers for epithelial-mesenchymal transitions. J Clin Invest 119:1429-1437 